\title{
Towards a post-fossil urban transport system: an actor-oriented approach
}

\author{
H. Hüging \& S. Böhler-Baedeker \\ Wuppertal Institute for Climate, Environment and Energy, Germany
}

\begin{abstract}
Mobility in urban areas offers a huge potential to decouple transport from fossil fuels. Energy efficiency and fuel diversification are key. Many policies and measures towards post-fossil transport are available, but information on implementation responsibilities is insufficient. The present paper goes beyond the definition of suitable policies and measures, but identifies key actors in transforming urban transport towards less oil dependency. It is analysed how each key actor can contribute to a post-fossil fuel transport system and their role in the development and realisation of policies and measures is defined. To describe the effects of each actor's activities, policies and measures are allocated to the four different components of a post-fossil transport system: system efficiency, travel efficiency, vehicle efficiency and alternative fuels. This process uncovers main actors for each building block of a sustainable transport system. The analysis shows that responsibilities for post-fossil transport are spread among different municipal departments and national ministries. Instruments to reduce the travel activity or to increase the share of energy-efficient modes are mainly in the responsibility of local authorities, whereas instruments to improve vehicle fuel economy and to introduce alternative fuels are in the hand of national ministries. Furthermore, many policies and measures need interdepartmental or interministerial support for successful implementation. Close cooperation between key actors is necessary to steer urban transport towards less fossil-fuel dependency.

Keywords: urban transport, energy-efficiency, actors, stakeholders, government, emissions, oil, policies and measures.
\end{abstract}




\section{Introduction - the need to reduce the transport sector's oil demand}

Most countries rely on oil as major source of energy in transport. It is known for decades that suitable oil reserves are declining leading to rising oil extraction costs (IEA [1]). Furthermore, fossil fuel combustion enhances the $\mathrm{CO}_{2}$ concentration in the atmosphere and thereby alters the global climate (Solomon et al. [2]). Even though some achievements have been made in terms of emission reduction and additional policies and plans have been announced, the global oil demand is projected to rise by $15 \%$ over the coming decades (IEA [1]). The transport sector is the main driver of global oil demand as its oil consumption is projected to quadruple. Driven by rising population and economic growth the increase in the transport sector's oil demand in emerging and developing countries is the main cause for rising oil consumption.

It is crucial to create more efficient systems for transportation in developing countries especially in urban areas. This is for three reasons: first, rapid population growth in developing and emerging countries is concentrated in cities (Cohen [3]); second, the growing income of the urban population drives motorisation (IEA [4]); third, as urban areas are densely populated and travel distances are rather short, there is a great potential to reduce energy consumption in urban transport.

Cars can only play a minor role in post-fossil urban passenger mobility. Instead, energy-efficient modes like public transport have to dominate and cycling and walking need to be facilitated by a dense city structure with short travel distances. The remaining fleet of motorised vehicles needs to be highly efficient and many of them have to run on alternative fuels. Post-fossil fuel transport is not only a reduced oil dependency in transport, but at the same time it is cleaner, safer and healthier than the current fossil fuel based transport system and offers economic advantages (e.g. Chang and Gou [5]; Woodcock et al. [6]).

To steer developments towards a post-fossil transport system is challenging especially as the governance of transport involves many actors at several governmental levels and within various non-transport sectors. In the following, strategies to reduce the fossil fuel consumption in urban passenger transport are outlined and the role of different governmental actors in steering the development towards post-fossil transport is investigated.

\section{A comprehensive approach to renovate transport}

A post-fossil urban transport system can be realised by enhancing the energy efficiency on different levels and by fostering a widespread use of alternative fuels. Altogether, four building blocks form a sustainable post-fossil urban transport system (Figure 1).

a) System efficiency is achieved by reducing the demand for transport to a minimum through a smart settlement structure. Research has shown that transport energy consumption per capita is inversely proportional to the density of a city (Newmann and Kenworthy [7]). 
b) Travel efficiency means that efficient modes like public transport and non-motorised modes dominate. Typically, passenger cars use more than twice the energy per passenger kilometre than public transport. Furthermore, improved trip organisation, which leads to high occupancy rates or load factors, reduces the energy consumption per person or tonne kilometre.

c) Vehicle efficiency comprises the use of fuel-efficient vehicles and efficient driving. Studies in developed countries estimate that the potential for an increase in fuel economy ranges between 20 and 30\% (IAC [8]). Furthermore, an efficient driving style can on average reduce the fuel consumption by around $10 \%$ (Smokers [9]).

d) Alternative fuels are used as substitution for fossil fuel based transport fuels. Currently, biofuels and electricity produced from renewable energy sources are the most promising alternatives to fossil transport fuels. In the long term, hydrogen produced from the electrolysis of water by using energy from renewables may become an additional alternative to fossil fuels (Kahn Ribeiro et al. [10]). However, in the medium term, non-oil based fossil fuels such as compressed natural gas $(\mathrm{CNG})$ can lead to reduced oil dependency and can lower greenhouse gas emissions.

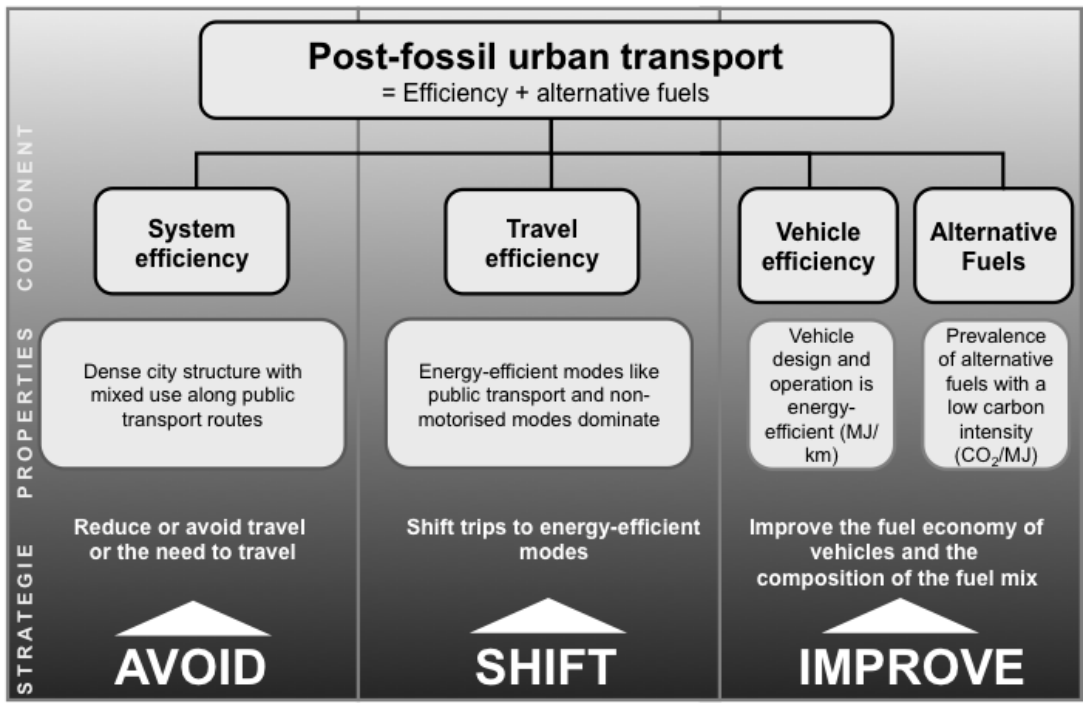

Figure 1: Building blocks of a post-fossil urban transport system (adopted from Böhler-Baedeker and Hüging [11]).

In order to develop a post-fossil transport system, decision-makers can follow the ASI (Avoid-Shift-Improve) approach, which was developed for greenhouse gas mitigation in transport (Dalkmann and Brannigan [12]). The ASI approach identifies three areas of action to reduce energy consumption and emissions from 
transport: first, avoid rising transport demand or reduce the existing demand; second, shift transport demand to more efficient modes; third, improve the vehicle fuel economy and the fuel mix.

Many policies and measures to reduce fossil-fuel consumption and emissions in the transport sector are available. A comprehensive overview about available policies towards sustainable road transport is provided by Santos et al. [13]. In the following section, example measures that address the different components of a post-fossil transport system are assigned to different actors in the transport system.

\section{Actors to develop a post-fossil transport system}

Steering the development towards a post-fossil transport system requires decision-makers to take the initiative. However, as a sustainable transport system includes a variety of elements, there is not the one actor that is in charge.

The following analysis is focused on the field of governmental actors on the national and local level, as the shape of the transport system is very much driven by their strategic plans, regulations and infrastructure provisions. The organisational structure of political authorities is simplified, as it is often very complex and differs largely between cities or countries. Key policies and measures are assigned to different actors on the national and local level at the end of each subsection (see Figures 2 and 3).

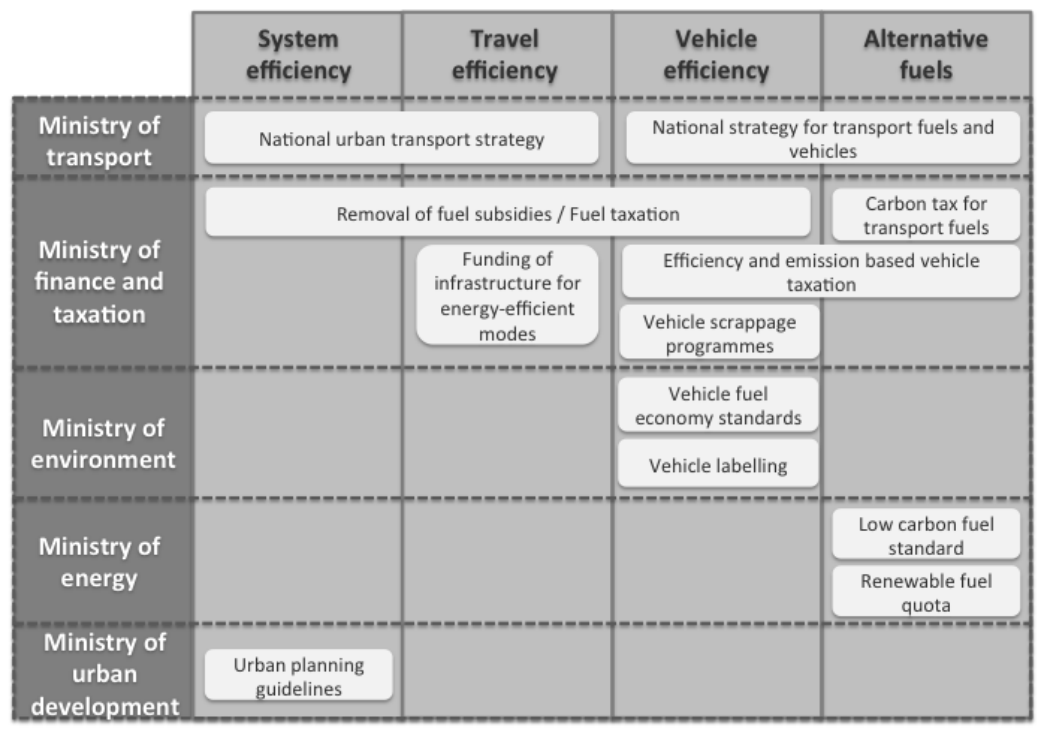

Figure 2: Overview about important policies and measures and responsible actors at the national level. 


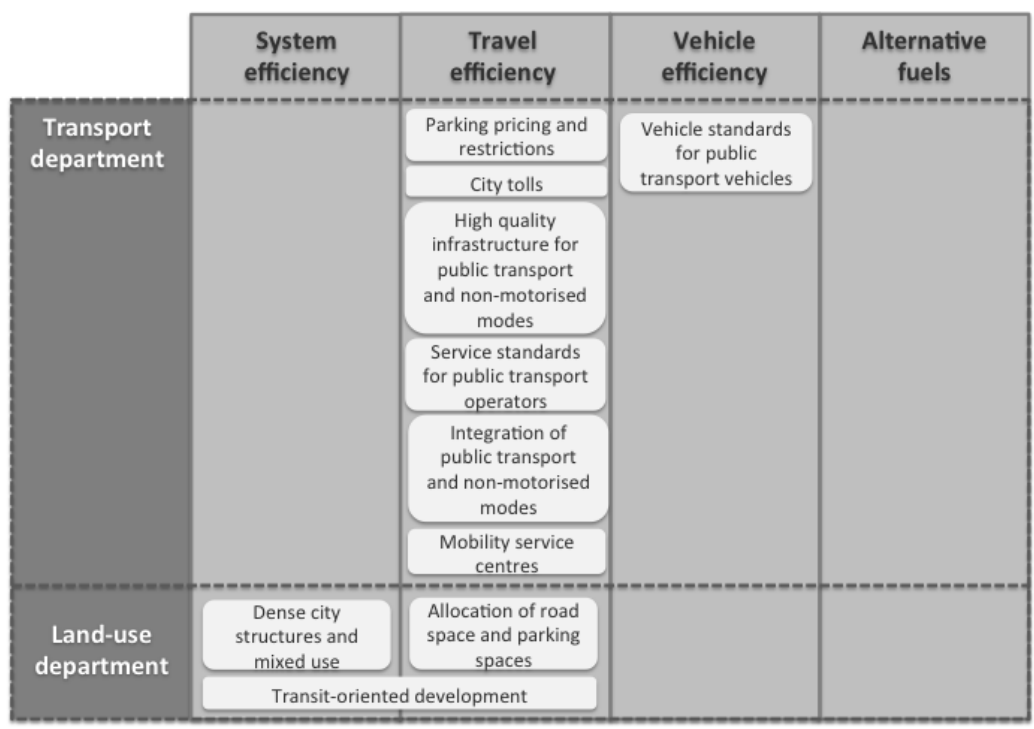

Figure 3: Overview about important policies and measures and responsible actors at the local level.

Often the development and implementation of one policy or measure involves several actors. Besides the actor responsible for the actual implementation, others can be engaged in the process by agenda setting - a group opens the discussion about a specific problem and exerts political pressure, consultation another actor provides information or formulates concerns during the design of a policy or measure, or by providing a legislative framework - an authority alters or sets regulations that make a policy or measure possible (Böhler-Baedeker and Hüging [11]).

\subsection{The role of the national government}

The national government can push the transport system of the whole country towards less dependency on fossil fuels. On the one hand, national policies and measures such as fuel taxation or vehicle standards can influence the whole transport system. On the other hand, national strategies, programmes and legislations frame local policies and national authorities decide about the bulk of the local budget for transport infrastructure.

Often functions that are related to urban transport are assigned to different ministries. The organisational structure of ministries and their responsibilities vary significantly from country to country. For instance in Indonesia the Ministry of Transport has the main responsibility for urban transport. In China, however, the Ministry of Transport is only responsible for public transport operation, whereas transport planning and urban development lies with the Ministry of Housing and Urban and Rural Construction (Dotson [15]). 
This fact is acknowledged, but to generalise the practice among states all ministries or intraministerial units that hold the main responsibility for a policy area are treated as one organisational unit.

\subsubsection{Transport ministry}

The transport ministry is responsible for the overall strategies and programmes for the transport sector and develops the national transport policy. Furthermore, the transport ministry is responsible for the integration of transport policies with other sectors and their strategies such as economic or environmental policies (Meakin [16]).

The ministry should assist local actors identifying and establishing suitable instruments towards low carbon transport. Dotson [15] points out that ideally national governments provide knowledge about national concerns such as oil dependency, climate change or local air pollution and address these issues by supporting dedicated research and pilot schemes for new policy initiatives. However, in many developing countries the national government does not fulfil this function and non-governmental organisations or international institutions try to fill this gap. The transport ministry needs to steer the development at the local level by outlining national strategies for urban transport and for transport fuels and vehicles. In India the 'National Urban Transport Policy' has been developed as a guiding document for urban transport improvements in Indian cities and included several principles of sustainable transport (Verma et al. [17]). In developing the overall strategy, the transport ministries can put many policies and measures, which have to be implemented by other ministries, on the agenda. Furthermore, the national transport ministry needs to provide guidance on the role of cities in reducing energy consumption can encourage local authorities to set their own reduction targets which are in line with the national target (Marsden and Rye [18]).

\subsubsection{Other national ministries}

Besides the ministries of transport, other ministries have administrative competences to implement policies and measures that address the transport system.

The competence of the ministries of finance and taxation is threefold. First, the ministries of finance set budgets and provide finance for transport infrastructure and services at different administrative levels. A close cooperation between the ministries of transport and the ministries of finance is required to ensure that the transport sector and especially infrastructure for sustainable modes obtain the financial resources necessary (Dotson [15]). Second, in consultation with the ministries of transport the ministries of finance can develop a tax system, which favours alternative fuels and energy-efficient vehicles. If subsidies for petrol and diesel fuels are in place, the ministries can reduce these subsidies and introduce fuel taxation. Fuel price increases are very useful to discourage the use of private cars and can promote fuel-efficient vehicles (Goodwin et al. [19]). Third, the ministries of finance can provide tailored financial incentives. For instance, tax rebates or grants can be provided for the 
use of public transport, for the scrappage of old and inefficient vehicles or for fuel-efficient vehicles.

The ministry of environment as well as its equivalents at lower governmental levels are typically responsible for the national policy for greenhouse gas emission mitigation. Thus, they are important agenda setters for policies that reduce emissions from transport. The ministries of environment are of high importance in ensuring that the national fuel strategy is sustainable. Especially renewable fuels have to be assessed with regard to their emissions over the whole lifecycle and the adverse environmental effects that can be associated with biofuel production (Howarth et al. [20]). The ministries of environment can create a legislative framework for biofuel production. Furthermore, the ministry of environment is a key actor in implementing vehicle fuel-economy standards.

The development of the national transport fuel strategy usually is with the ministry of energy. It can implement specific policies to increase the share of renewable fuels such as low carbon fuel standards or renewable fuel quotas (see Yeh and Sperling [21]; Creutzig et al. [22]). The ministry's long-term fuel strategy is key to reduce the oil dependency of the country's transport system. Further, the ministry of energy is responsible for electricity production. In light of technological advance in electric drive systems and battery electric vehicles an increase in electricity production from renewable energy sources is important to exploit the emission reduction potential that electromobility offers (Samaras and Meisterling [23]).

Several countries such as India have separate ministries that deal with urban development. The ministry of urban development can implement urban planning guidelines that follow the principles of high density and mixed use.

The ministries of economics, industry and technology can be involved in several policies and measures such as vehicle or fuel standards as they gather knowledge about the latest technical advances in vehicle and fuel processing technologies. The ministries can promote technological progress in transport technologies by initiating and supporting research and pilot projects.

Often there are conflicting interests between the different actors that are involved or even within the same department or ministry. For instance, the ministry of economics may seek to support the national vehicle manufacturing industry and therefore pushes road infrastructure and car oriented development (Dotson [15]).

\subsection{The role of the local government}

There are many policies and measures for sustainable urban transport that should be in the responsibility of authorities at the local level. Local authorities are aware of the specific problems and challenges a city faces and can develop suitable policies. They need sufficient decision-making power and control over financial means. This also encourages local bodies to take ownership of problems (Dotson [15]). The responsibilities of local authorities are usually in the field of spatial planning and infrastructure planning. Furthermore, at the local level regulatory measures for car use or increases in the attractiveness of 
alternatives to the private car can induce a behaviour change towards more energy-efficient modes and mobility patterns.

The mayor can play a curial role in steering the development towards postfossil transport. In some cities, local administrations have to seek approval for policies and measures from the mayor and the city council; in others the mayor even gives instructions to the local agencies. Thus, the mayor's influence can be very high (Dotson [15]). It is essential that the mayor seeks expert advice from the local departments. Because of their legitimacy, the mayor and the city council can develop an overall strategy for increased energy-efficiency and low carbon development. Quantitative and qualitative targets can be outlined for different sectors including transport.

As experiences in Bogotá, Seoul or Curitiba show, mayors that provide visions and leadership can have huge impact on the development of the city. Leadership is key in urban transport projects (Ponnaluri [24]). The overall concept of sustainable transport needs strong political support and specific projects might require the engagement of strong leaders to overcome upcoming barriers to implementation. Without leadership and political courage to encounter the claims for additional roads and car-friendly infrastructure investments, cars will dominate and the quality of public transport will be deteriorated ( $\mathrm{Li}[25])$.

The heads of the local bodies need to ensure that there are no overlaps in responsibilities and that different municipal departments cooperate smoothly, work into the same direction and that their efforts intertwine. Further, they have a key role in ensuring a transparent policy-making, including disclosure of information, public participation and sanctions for corrupted activities. However, in many countries these principles of good governance are not yet manifested in the institutional framework (Dotson [15]).

\subsubsection{Transport department}

There is a variety of practices with regard to the organisation of local transport in developing and emerging countries as well as in developed economies. Most cities have specialised transport departments and often these departments are further divided into several organisational units. Transport planning and transport management are typically two key branches within the transport department. Often, separate bureaus are responsible for the different modes of transport (Meakin [16]).

Groenewald [26] differentiated four categories of how the transport function is being taken care of in different countries or cities around the world. The categories differ in terms of the allocation of tasks, the inclusion or separation from local government structures and administrative boundaries. For example, in some cities, the transport planning and management is in the responsibility of one or more municipal departments and private sector operators have contracts for public transport provision, but can obtain specifications on timetables and fares from the local government. Some countries, such as Germany, have dedicated public transport authorities, which are separated from the local government structures and cover larger regions. Another approach for managing 
transport functions, is the composition of an integrated transport organisation which includes governmental representatives from different levels and which is responsible for planning and decision-making. Only executive tasks remain with the local government. In contrast in some counties, such as Singapore, planning, decision-making as well as executing responsibilities rest with a single transport authority.

Several countries aim at developing a transport authority that operates at a higher level and can consist of several municipalities to meet the demands of dominant passenger movement across municipal boundaries (Marsden and Rye [18]; Groenewald [26]). For a post-fossil transport system such an institution can have multiple benefits especially in growing urban agglomerations. Public transport networks, services and fares can be integrated resulting in enhanced attractiveness of the systems. However, if implemented as a voluntary option, it is unlikely that local authorities will pass powers and funding to these institutions (Marsden and Rye [18]). Furthermore, these institutions need clear responsibilities, financial arrangements and experienced and skilled personnel (Groenewald [26]). If the permanency and power of such an institution is unclear, such a development can even inhibit the transition towards a post-fossil transport system.

The authorities responsible for local transport can implement a variety of policies and measures towards post-fossil transport. The planning division can encourage mode shift by developing a high quality infrastructure for nonmotorised modes and by planning a public transport network, which is attractive and demand-oriented. The traffic management division can reduce car use by a number of regulatory measures such as parking charges, restriction of on-street parking or city tolls. Furthermore, the reliability and travel time of public transport can be improved by signal priority. Service standards can require public transport operators to improve the quality of vehicles, stations and services.

Besides the implementation task, the local transport department has to act as an agenda setter for policies and measures towards sustainable transport that are in the responsibilities of other departments. Close cooperation and consultation needs to take place between the local land-use departments and the public transport operators, which are typically private or parastatal enterprises.

\subsubsection{Land-use department}

Typically separate departments manage land-use planning and urban transport planning, although land-use and transport demand are closely correlated. Often the land-use planning department focuses on managing the expansion of the city and while roads are included to attract new industries and businesses, the role of public transport and non-motorised modes is often neglected. The land-use planning department can considerably contribute to a higher system efficiency of transport by focusing on brownfield developments and urban renewal. Where an expansion of the settlement structure is inevitable, planners can reduce the increase in car travel by following the principles of mixed use and transitoriented development meaning that new settlements are constructed along public 
transport routes. Further, to facilitate a development towards post-fossil transport, land-use planning can ensure that infrastructure for non-motorised modes is well integrated in new settlement structures and the road and parking space for cars is limited. However, many developing and emerging economies experience rapid urbanisation and the land-use planning department struggles to keep pace with developing land-use plans and providing public transport services, which leads to suboptimal land-use structures and car dependency (Dotson [15]).

To limit the rapidly growing transport demand especially in expanding urban agglomeration, land-use planning and transport planning need to closely cooperate. Best both functions are combined in a single department or agency.

\subsubsection{Other local departments}

In addition to the transport and the land-use departments, the department of finance is a key actor in urban transport. Even though the department has no direct implementation responsibilities, it sets the budgets and provides the finance for transport infrastructure. Therefore, the financial department needs to be consulted for all transport related measures that require funding and maintenance and operation costs need to be uncovered (Dotson [15]). Besides funding from higher governmental levels, many cities can raise their own funds by city tolls, fuel surcharges or parking pricing. For these revenue generating transport policies the financial department can act as an agenda setter and can be involved in the implementation of these measures.

\section{Conclusion}

The analysis has shown that many governmental actors are involved in transport policy making. Only if a variety of decision-makers and stakeholders cooperate a sustainable development will succeed. On the national level, transport ministries can set an overall strategy for urban transport systems as well as for vehicles and fuels. The national level holds the main responsibility in improving vehicle efficiency and fossil fuel substitution, but these areas are typically in the responsibility of non-transport ministries. Many effective measures to induce mode shift towards energy-efficient modes and to reduce travel demand are best in the responsibility of local actors. However, there are a variety of barriers that inhibit the implementation of policies and measures for post-fossil transport and unclear responsibilities is only one of them. In some countries, local governments only have very restricted decision-making power or the national government fails to develop an overall strategy and to provide dedicated funding. Non-governmental actors such as development banks, local banks, nongovernmental organisations, research institutions or development organisations sometimes take up some of these tasks and enable cities to overcome knowledge gaps, capacity insufficiencies or financial barriers. Furthermore, the public has a key role in steering the development towards post-fossil transport as ideally it elects the decision-makers at different governmental levels and can influence the selection and design of policies and measures via public participation processes. 


\section{References}

[1] IEA - International Energy Agency, World Energy Outlook 2011, OECD/IEA: Paris, 2011.

[2] Solomon, S., Qin, D., Manning, M., Chen, Z., Marquis, M., Avery, K.B., Tignor, M. \& Miller, H.L. (eds), Contribution of Working Group I to the Fourth Assessment Report of the Intergovernmental Panel on Climate Change, Cambridge University Press: Cambridge, UK, 2007.

[3] Cohen, B., Urbanization in developing countries: Current trends, future projections, and key challenges for sustainability. Technology in Society, 28, pp. 63-80, 2006.

[4] IEA - International Energy Agency, Transport Energy and $\mathrm{CO}_{2}-$ Moving toward sustainability, OECD/IEA: Paris, 2009.

[5] Chang, S.K. \& Gou, Y.J., Trip Cost Analysis of Bus Rapid Transit. Proceedings of the Eastern Asia Society for Transportation Studies, 5, pp. $2195-2210,2005$.

[6] Woodcock, J., Edwards, P., Tonne, C., Armstrong, B. G. et al., Public health benefits of strategies to reduce greenhouse-gas emissions: urban land transport. The Lancet 374, pp. 1930-1943, 2009.

[7] Newman, P.W.G. \& Kenworthy, J. R., Cities and Automobile Dependence: An International Sourcebook, Gower: Aldershot, UK, 1989.

[8] IAC - InterAcademy Council, Lighting the way. Toward a sustainable energy future. InterAcedemy Council: Amsterdam, 2007.

[9] Smokers, R., Vermeulen, R., van Mieghem, R., Gense, R., Skinner, I., Fergussion, M., et al, Review and analysis of the reduction potential and costs of technological and other measures to reduce $\mathrm{CO}_{2}$-emissions from passenger cars. Final report on behalf of the European Commission (DGENTR), 2006.

[10] Kahn Ribeiro, S., Kobayashi, S., Beuthe, et al, Transport and its infrastructure. In: B. Metz, O.R. Davidson, P.R. Bosch, R. Dave, L.A. Meyer (eds), Climate Change 2007: Mitigation. Contribution of Working Group III to the Fourth Assessment Report of the Intergovernmental Panel on Climate Change Cambridge University Press: Cambridge, 2007.

[11] Böhler-Baedeker S. \& Hüging, H., Urban transport and energy efficiency, Sustainable Urban Transport Sourcebook, Module 5h, (forthcoming).

[12] Dalkmann, H. \& Brannigan, C., Transport and Climate Change. Sustainable Urban Transport Sourcebook, Module 5e, GTZ: Eschborn, 2007.

[13] Santos, G., Behrendt, H., Maconi, L., Shirvani, T. \& Teytelboym, A., Part I: Externalities and economic policies in road transport, Research in Transport Economics, 28, pp. 2-45, 2010.

[14] Santos, G., Behrendt, H. \& Teytelboym, A., Part II: Policy instruments for sustainable road transport, Research in Transport Economics, 28, pp. 4691, 2010.

[15] Dotson, E., Institutional and political support for urban transport (Chapter 10) Urban transport in the developing world: A handbook of policy and 
practice H.T. Dimitriou \& R., Gakenheimer (eds), Edward Elgar: Cheltenham and Northampton, pp. 262-301, 2011.

[16] Meakin, R., Urban transport institutions, Sustainable Urban Transport Sourcebook, Module 1b, GTZ: Eschborn, 2004.

[17] Verma, A., Sreenivasulu, S. \& Dash, N., Achieving sustainable transportation system for Indian cities - problems and issues. Current Science (Bangalore), 100(9), pp. 1328-1339, 2011.

[18] Marsden, G. \& Rye, T., The governance of transport and climate change. Journal of Transport Geography, 18, pp. 669-678, 2010.

[19] Goodwin, P., Dargay, J. \& Hanly, M., Elasticities of road traffic and fuel consumption with respect to price and income: A Review Transport Reviews, 24(3), pp. 275-292, 2004.

[20] Howarth, R.W., Bringezu, S., Bekunda, M., de Fraiture, C., Maene, L., Martinelli, L. \& Sala. O., Rapid assessment on biofuels and environment: overview and key findings', Biofuels: Environmental Consequences and Interactions with Changing Land Use. eds. R.W. Howarth \& S. Bringezu, Proceedings of the Scientific Committee on Problems of the Environment (SCOPE) International Biofuels Project Rapid Assessment, 22-25, 2009.

[21] Yeh, S., \& Sperling, D., Low carbon fuel standards: Implementation scenarios and challenges, Energy Policy, 38(11) pp. 6955-6965, 2010.

[22] Creutzig, F., McGlynn, Minx, J. \& Edenhofer, O., Climate policies for road transport revisited (I): Evaluation of the current framework, Energy Policy, 39, pp. 2396-2406, 2011.

[23] Samaras, C. \& Meisterling, K., Lifecycle Assessment of Greenhouse Gas Emissions from Plug-in Hybrid Vehicles: Implications for Policy' Environmental Science and Technology, 42, pp. 3170-3176, 2008.

[24] Ponnaluri, R. V., Sustainable Bus Rapid Transit initiatives in India: The role of decisive leadership and strong institutions. Transport Policy, 18, pp. 269-275, 2011.

[25] Li, J., Decoupling urban transport from GHG emissions in Indian cities - A critical review and perspectives. Energy Policy, 39, pp. 3503-3514, 2011.

[26] Groenewald, H., Establishment of transport authorities in local sphere of government in South Africa: unfolding of the process. Transport Policy, 10, pp. 1-15, 2003. 